
\title{
28 Research Square \\ TRPP2 and STIM1 play a combined role in maintaining blood vessel health
}

Jizheng Guo

Ren Zhao

Muyao Zhou

Jie Li

Xiaoqiang Yao

Juan Du

Jiexia Chen

Bing Shen

\section{Video Byte}

Keywords: Cell Communication and Signaling, polycystin-2, TRPP2, stromal interaction molecule 1, STIM1, vascular smooth muscle cells, VSMC, store-operated Ca2+ entry, SOCE, blood vessel tone, calcium signaling, synergy, fluorescence resonance energy transfer, FRET, vessel contraction, 2-aminoethyl diphenylborinate, 2APB, aorta, PKD1, PKD2

Posted Date: November 12th, 2020

DOl: https://doi.org/10.21203/rs.3.rs-106656/v1

License: (9) This work is licensed under a Creative Commons Attribution 4.0 International License. Read Full License 


\section{Abstract}

TRPP2 and STIM1 are important proteins that facilitate the transport of calcium ions in the cell. TRPP2 is a calcium channel encoded by the PKD2 gene, which is mutated in polycystic kidney disease. STIM1, meanwhile, acts as a calcium sensor, monitoring and regulating calcium concentrations. For the first time, researchers have demonstrated that the two proteins form a functional complex in embryonic kidney cells and native vascular smooth muscle cells. Together, TRPP2 and STIM1 modulate storeoperated calcium entry to maintain cellular calcium balance. In mice, that synergy protected against agonist-induced contraction of the aorta, suggesting that the TRPP2-STIM1 complex helps maintain blood vessel tone. Further studies could help clarify the full functional repertoire of the TRPP2-STIM1 complex and harness this powerful duo to keep blood vessels healthy in patients. 